\title{
Silent Pain of Caregivers: A Qualitative Study
}

Dr. Jaya Bharti ${ }^{1 *}$ and Prof. Pallavi Bhatnagar ${ }^{2}$

${ }^{1}$ Assistant Professor Department of Psychology A.N.D.N.N.M.M. Harshnagar Kanpur, Kanpur University, India

${ }^{2}$ Former HOD, Department of Psychology, University of Lucknow, UP, India

DOI: $\underline{10.36348 / \text { sjhss.2020.v05i07.001 }}$ | Received: 01.07.2020 |Accepted: 09.07.2020 | Published: 15.07 .2020

*Corresponding author: Dr. Jaya Bharti

Abstract

Background: Both theoretical and empirical evidences on chronic illness suggest negative consequences of caregiving on the psychological wellbeing and Quality of Life (QOL) of the caregivers. However, the fact remain that there is a paucity of empirical researches on the quality of life of caregivers of people with chronic mental illness. Purpose: The purpose of the present research is to assess the Emotional Quality of Life among caregivers of person with chronic mental illness across gender. Setting: Psychiatric Hospitals and clinics Lucknow, Uttar Pradesh, India. Participants: The sample comprised of 100 primary caregivers of person (50 were male caregivers and 50 were Female caregivers) with diagnosed chronic mental illness of Schizophrenia, Anxiety Disorder, Personality disorder, Depression and Bipolar affective disorder (BPAD). Those willing to participate in the study were interviewed to assess their Emotional quality of life. Results: The female caregivers painfully construe caregiving as sadness and also attribute caregiving to be the source of their sadness in life. Somewhere there is a fatalist attitude adding greater pain in their life and they cope with pain and sadness largely by crying. On the other hand, male caregivers have reported painful and conflictual relationship with the patient as the perceived meaning of sadness and pain both. However, they cope up with the same by moving away and sharing with people. Globally the self-image of the caregivers is negative more specifically after the caregiving. The narratives of the caregiver are subsumed in a model. Conclusions: The findings of the study serve as the roadmap for furthering researches into emotional wellbeing of the caregivers of the person with chronic mental illness. Largely the attention is more towards creating intervention for the patients suffering from mental illness. Such studies would serve as the base for creating and improved emotional Quality of life for the caregivers.

Keywords: Chronic mental illness, Emotional quality of life, caregiver, qualitative research etc.

Copyright @ 2020: This is an open-access article distributed under the terms of the Creative Commons Attribution license which permits unrestricted use, distribution, and reproduction in any medium for non-commercial use (NonCommercial, or CC-BY-NC) provided the original author and source are credited.

\section{INTRODUCTION}

Chronic illness affects not only the lives of those suffering from disease but also those of family members who care for them. Attending to the impacts of chronic illness on family members is important because the physical and emotional health of family caregivers has the potential to influence the health, welfare and successful rehabilitation of persons with such chronic illness [1].

Researches on Caregivers of person with chronic illness represent diseases like Cancer [2, 3], Stroke [4], Traumatic Injury [5] Sclerosis [6] HIV/AIDS [7, 8] Coronary Heart disease [9, 10] Asthma, arthritis, diabetes, heart disease [11, 12, 13] Hepatitis C patients [14] Inflammatory bowel disease [15]. These and many such studies clearly suggest the overrepresentation of people with physical disorder as sample in researches on chronic illness. However there seems to be a vacuum with reference to the sample of mentally ill people. Further when caregiver of the patient of chronic illness are addressed, the same trend of underrepresentation of the caregiver of mentally ill patient is evident. Although a significant trend which emerges showed high anxiety, depression and low quality of life. [ 16], researches also showed evidence of negative feelings like anger, guilt feeling, fear, hopelessness, sadness, and negative feelings and attitudes toward the patient $[17,18]$, as well as this dissatisfaction with their health and poor QOL [19].

According to Dalui, Guha, De, Chakraborty \& Chakraborty [20] the Caregivers may experience reduced productivity at home and in the workplace, thus losing wages. This combined with the health care costs for the patients diagnosed with severe mental illness affects the caregivers' financial situation. Caregivers are also prone to experiencing social consequences including; disrupted social networks, stigma and 
discrimination, which exposes them to high levels of depression, stress and anxiety [20, 21, 22, 23]. These finding also suggest negative consequences of caregiving on the psychological wellbeing and Quality of Life (QOL) of the caregivers. However, the fact remain that there is a paucity of empirical researches on the quality of life of caregivers of people with chronic mental illness.

Srivastava [12] \& Verma [24], observed that the lower the QOL of caregiver, poorer the psychological wellbeing. Further it has been found that the caregiving role usually adds responsibilities on the caregivers' daily life, and occupies their time, energy, and attention. [25-30, 26, 31-34]. Taking the backdrop of the heavy emotional consequences of caregiving, the present research paper addresses the emotional dimension of Quality of Life of the caregivers of chronic mental illness, as the review of almost all the researches on the caregivers of chronic ailment clearly suggests an over pervasive dominance of emotional component viz: Heightened depression, anxiety, fear, which also become a rational for addressing emotional quality of life in the present study.

\section{METHOD \\ Objective}

- To assess the Emotional Quality of life among the caregivers of person with Chronic Mental Illness across gender.

For this an Ex-post facto research design was used. Initially a survey of the Psychiatric Hospitals in Lucknow was made by the researcher. After this on the basis of the inclusion criterion, some Private Psychiatric Hospitals in Lucknow were picked up. Emotional Quality of Life was the major variable explored across Gender

The sample comprises of 100 primary caregivers of person with diagnosed chronic mental illness of Schizophrenia, Anxiety Disorder, Personality disorder, Depression and Bipolar affective disorder (BPAD) coded with male caregiver A1-50 and A51-100 for female caregivers from Private Psychiatric hospitals and clinics at Lucknow, Uttar Pradesh, India.

Quality Of Life Interview Schedule (developed by researchers) was used to assess the Emotional quality of life of primary caregivers of the person with chronic mental illness. Present Schedule has four dimensions (Physical, Relational, Emotional and Environmental). The present study has only taken up the Emotional Dimension of the caregiver which comprises 18 items. The data obtained from Emotional dimension was exhaustive. Thereafter 14 themes of caregivers emotional QOL emerged from the caregiver interviews however five major themes out of these are being shared in this paper.

\section{RESULTS AND DISCUSSION}

To bring a change in the perspectives and outlook of caregivers towards mental health, it is essential that they have an improved Quality of Life. Before making any effort towards improving Quality of Life of caregivers, it is essential to find out their present status. Content analysis was done. For each dimension the result are being shared. The most frequent themes are being given in the Figure1 (THE RESEARCH AT A GLANCE -THE MAJOR THEME).
A. Sadness: Semantic and Source
B. Pain: Perceived meaning and coping
C. Going through the process of caregiving: works liked \& Disliked
D. Perception towards Life
E. Self-Image prior and after caregiving

\section{A. Sadness: Semantic and Source}

A significant characteristic feature of the emotional climate of the families with chronic mentally ill patients is sadness or melancholy.

How do caregivers construe sadness, as well as, its perceived causes/sources brought forth some painful experiences from the caregivers. Five major response categories were (1) Being a Caregiver (2) Loneliness (3) Sickness \& Pain (4) Conflictual relationship (5) Don't know.

Whereas sadness was construed as predominately "being a caregiver" for the females $(88 \%)$, it was seen as "Conflictual relationships" with the patient I take care for the males (80\%), the narratives clearly speak for themselves.

\section{For the female caregiver the narrative : Experienced sadness}

"The responsibility that I am carrying is the sadness for me.... Whole life was ruined due to this. Relationship with family members is broken, in-laws also never talk..... Nobody still happy after doing this painful work, I felt very isolated at home"(A55).

"I am a lot more tired...it makes me feel so stressed out, I have lost $13 \mathrm{~kg}$ " (A97).

"No one talks to me, nor I want to talk to anyone. It is written in my destiny to die like this.... I feel negative about things and I don't look forward to the future"(A79).

\section{For the male caregiver the narrative: Experienced sadness}

"She is not my wife anymore...we don't have a relationship....I am her caregiver....our marriage ended with her illness....she has her room and I have mineher illness, sick behaviour, and caregiving have affected my relationship and my children's too...... I often feel sad and depressed" (A19). 
"I am more irritable than before and it has made me more anxious and nervous-I was looking forward to this part of our lives and we never expected this - it has taken away our dreams"(A39).

He"s not my husband anymore-we don"t have a relationship - I am his caregiver - our

Marriage ended with his stroke- - he has his room and I have mine- his stroke and

Caregiving have affected my relationship with his children - they have alienated me

He"s not my husband anymore-we don"t have a relationship - I am his caregiver - our

Marriage ended with his stroke- he has his room and I have mine-his stroke and

Caregiving have affected my relationship with his children - they have alienated me

Empirical support from Corcoran [40]; Bush [41]; Almada [42]; Campbell [43] suggest role-conflict due to conflicting and incompatible demands overwhelming one's ability to carry out one's role and caregivers feeling of being trapped in their roles. The anguish and pain of the caregivers was clearly evident in their responses recorded verbatim by the first author. Sadness is an emotional pain associated with, or characterized by, feelings of disadvantage, loss, despair, grief,

helplessness, disappointment and sorrow. An individual experiencing sadness may become quiet or lethargic, and withdraw themselves from others. Content analysis brings to fore response categories were (1)Problems in relationship (2) Being a caregiver (3) Relative (4) Lackness of money (5) Don't know.

\section{For the female caregiver the narrative: Source of sadness \\ "The reason of my sadness is only caregiving"}

(A75)

"I am dying taking care of my husband..........I am more irritable than before and it has made me more anxious and nervous......" (A89).

"These conflicts and painful relation with the person I am taking care of is draining me......making me more sad and hopeless day by day."(A51).

\section{For the male caregiver the narrative: Source of}

\section{sadness}

"I feel that it is my duty to help him in his present difficult circumstances. That is why I am serving them. Because of which there is discord in my house, my wife helps me in this but she also fights. Children are also worried".(A21)

"Such a house is a house where there is no laughter and happiness. I feel like dying. Don't want to come back home......always fight-fight". (A05)
I have lost 30 pounds (P11); “"II am tired all the time... I don"t have any energy I have lost 30 pounds (P11); “"I am tired all the time... I don"t have any energy

As given above varying estimates across different countries indicate that $57 \%$ to $81 \%$ of all caregivers of the chronically ill are women $[12,35,36$, 37].

\section{B. Pain: Perceived meaning and coping}

Content analysis of data brought forth five significant response categories of : (1) Destiny(2)Helplessness(3)Personalized event(4)Present status of family(in terms of sickness \& financial constrains) (5)Don't know. The semantic of pain in female caregivers seems to bring out predominantly the element of "Destiny" (50\% female caregivers) or remaining $50 \%$ female caregivers reported felt "Helplessness" with narrative:

\section{For the female caregiver the narrative: Experienced} pain

"This responsibility I am carrying is the same misery for me, for this, my whole life was ruined, there is no happiness in my life, I have a lot of problems"(A69).

"My fate is very bad.....I still go out to temple and a few other places like my mother's home but I can't stay very long. It is better to die than to live. So I feel very tired and I wish I was no more"(A52).

"We tried many places for treatment, starting with the Faith healers and Tantricks after spent a lot of time in this, reach out to mental hospital in Uttar Pradesh, India. That didn't help, so then we didn't go anywhere. Later he got shock (ECT) treatment by psychiatrist, but that didn't help either. He relapsed in 2005 and again from 2013 onwards, I am very much tired now.... I don't have any time for myself, I have nothing in my hand"(A97).

While for male caregivers (86\%) it is once again the strained relations and heavy demands which superimpose destiny, helplessness, worthlessness etc. The narrative below corroborates the same.

\section{For the male caregiver the narrative: Experienced pain}

"I am juggling between my job, my wife and children, my father's business and caring for my mother - sometimes I can't see any light at the end of the road, I cannot express openly to my relatives about the mental illness of my mother after knowing this no-one wants to marry in my family. ..... I am very much worried, why its only happened with my family "(A14). 
"I cannot go out for any longer than 30-60 min - I always feel rushed when I go out - rushed to go to the hairdresser, for shopping the domestic items and rushed to see my doctor"(A44).

For exploring coping strategies in terms of coping with pain. The content analysis of data suggests brought forth some significant response categories viz: (1)Rest (2)Silence (3)Sharing with others(4)Crying (5)Do nothing. As clearly evident in figure, the coping with pain seems to go with the gender typing reinforced in the society with most female caregivers reporting that they "cry" for coping with pain.

\section{For the female caregiver the narrative: Coping with pain}

"Whenever I am in pain, I look around and cry alone, he doesn't appreciate any of the things I do for him - he never says thank-you - he asks for more help than he needs.....then I cry a lot"(A99).

"Ever since I got married I could not go home, I was engaged only in care. I do not remember when I last spoke to my mother and father... I cry a lot, I cry alone... no one To whom I can tell my trouble"(A60)

On the other side male caregivers report "sharing with others" to unburden the load of pain.

\section{For the male caregiver the narrative: Coping with pain}

"Every day there is ruckus at home, so when it hurts me, I go to meet my friends and talk to them...... My Friends helps me - they calls every day to see how I am doing because they knows this is very hard for me"(A12).

"As long as I am in office, I am fine, but I do not feel like going home as soon as evening. I go to my friends, I sit near them for a long time.....but also worry about the house" (A33).

This finds an echo in the findings of Aşiret [38] who found that Caregivers" strategies for coping with the problems were sharing their feelings with others (43.2\%) and crying (35.3\%). Srivastava G, Tripathi RK, Kumar A, Tiwari SC [39]. Observed that "Social relationships" QOL was found better of males compared to females. Females are more dissatisfied in their personal, social, sexual life, and they do not get enough support from their friends and other family members to share their responsibilities.

\section{Going through the process of caregiving: works liked \& Disliked}

Content analysis brings to fore few responses categories viz: (1) To give food (2) Not like anything (3) Don't know(4) all work (5) Spending time. As one would except the nurturing part of the female caregiver overwhelmingly responded that what they liked most about caregiving was "Giving food" (82\%) to the patient with verbatim:

\section{For the female caregiver the narrative: caregiving works liked}

"I always took care of people by giving food so I never felt that that was going to be the wrong thing to do... I just took it as that was part of my life goal, to take care of them through food learnt by my mother who cared others selflessly... It's stressful, but sometimes it's rewarding........ I couldn't like say, I can't do this. It's just not in me"(A59).

"I like to cook and feed. When someone eats food that you have made with love, you feel good, the heart is relieved....even today, people have forgotten to praise... guests do not even ask for food, but I am not like this" (A70).

On the other hand their counterpart responded that they "not like anything" about caregiving (86\%) with responses like:

\section{For the male caregiver the narrative: caregiving works liked}

"After a very long time, I was getting a dream job which perfectly suits me... 2-3 months into the job, mother fell down and broke her hand, She is not in the condition to take care of my wife(patient) and manage household chore ... so then I could not continue job, then I had my son ... it was rest, complete nine months rest ... Now I do want to (work), children are older. I want to go for some job somewhere close-by.....but there is no one to help me.... feeling helpless......my whole life is spoiled, my career, my status and relationship......this caregiving took everything, I am worthless......I don't want to do nothing.... I hate this"(A48)

"No man likes to do household work. If a man does household work, he does it under compulsion, I believe. I also have helplessness so I am doing it otherwise I do not like it at all'(A25).

The other side of the caregiving was what part of caregiving they did not like. This has been somewhere imbibed in the gender script of the women that they are suppose to be nurturant, lonely, loving, caring, taking care of the children, elderly, and the sick people in the house (National Alliance for Caregiving and AARP Public Policy Institute [44]. Content analysis brings to fore few responses categories viz: 1) Daily routine activities 2) To give attention all the time 3) Toilet 4) All works 5) Nothing to say. However, in the care of caregiver of the chronic mentally such persons somewhere their tolerance is also reaching its threshold, with responses like: 


\section{For the female caregiver the narrative: caregiving} works disliked

"I am completely trapped - I can't go anywhere anymore - I don't have any time for myself... I have no life.... don't get things done around the house - I can't go out for too long in the evening because I have to come back and put her to bed- my time is limited and I feel pressured with the time I have.... I stopped employment completely because of caring for my mother"(A85)

"Throughout the day, I keep serving my father-in-law only. After seven years of marriage, my husband has not thought for family planning yet. We both are engaged in service day and night, there is no time for each other. Now I feel suffocated" (A94)

$84 \%$ female caregivers felt overwhelmed with this over demanding role of "giving attention all the time". On the other hand there counterpart clearly stated at they "did not like to attend to the daily chores" of the patients $(86 \%)$ reported so viz:

\section{For the male caregiver the narrative: caregiving works disliked}

"When I awake up in the morning, change diapers 4-5 times prepare breakfast and feed her, then clean house also take care my shop too. Afterwards, at noon, change diapers 13 to12 times and serve lunch. In the evening, I come home, after closing shop which is open in my house, I take over the caregiving work again, In the meantime my children take care of her.... That way, I'm somehow able to get by each day.... I don't like doing all this, don't know why I'm doing this"'(A33).

"A few days after my wedding, it is revealed that my wife is mentally ill, her parents hide her illness. My family members married me because of that someone could gave me delicious food and take care of me, but here everything is turned upside down... Now all the household work has to be done by me as utensils, clothes....I do not like this, hate this" (A19).

\section{Perception of Life}

Content analysis brings to fore few responses categories viz: (1) Hopeless (2) Satisfied (3) Neither good nor Bad (4) Personalized Negative (5) Nothing to say. The world view and one's perception of life gives a window into the emotional wellbeing of the individual what appeared prominently was a rather dismal picture, that is, most of the female caregivers expressed empty void of hopelessness, and feeling trapped (78\%) said "nothing to say" about life with verbatim like:

\section{For the female caregiver the narrative: perception of life}

"Doesn't want to say anything.... don't feel anything, No words for defining this, feel nothing..........nothing...... Now every woman want to work and live .....They can't sit at home... They want to go out.... When I got married I was working as a Primary teacher. After one year of marriage parents-inlaw and husband suggested me to stop and come back .....So, I suddenly quit my job which is my biggest mistake and came back here, many things I do compromise. Sometimes, I would get angry on myself even self harming tendency also develop"(A82).

"Do you think that I am living a life... It is a life... He has to live to tell about life...I have not only lived my life, but I have only drunk sip of poison.......so what to say, nothing to say" (A78).

The male caregivers predominantly reported life as "hopeless" (82\%). Family caregivers play many roles in caring for persons with mental illness, including day-to-day care, medication supervision, taking the patient to hospital, and caring for financial needs. The family caregiver also has to bear with behavioral disturbances in the patient [45].

\section{For the male caregiver the narrative: perception of} life

"There is no hope in life, now i am very anxious....... Every morning when I wake up feel low, I do not know what the day will be like ...... will anyone smile in my house today or will there be trouble and grief like every day. I feel more confined helpless and worthless. I do not know when this disease will be cured, I do not know how the disease got"(A36).

"Life is very sad ....nothing is left, my mind is lost now, I don't think anything is going to be alright ... just going on ...... see what happens. I have failed in the exam of life" (A24).

Lack of support, empathy and help from within the family \& outside family seems to contribute a lot in developing a negative perception of life. Ignorance of family members in regards to the nature of mental illness was said to be a contributing factor to lack of support which increase the passive pain of the caregiver. Caregivers described feelings of helplessness related to the fact that no one else was willing to help them. Many caregivers described people around them having negative attitudes toward their mentally ill relative that's why they don't meet and greet with others and feel isolated [45].

\section{E. Self-Image prior to and after caregiving}

Self: the inner core which provides the driving force and striving to achieve the goals of life comprises of not only "I" or "me" but the relational self of I" as others see me particularly in Indian context with the cultural ethos of VASHUDHAV KUTUMBKUM (whole world is a family). The "WE" somewhere overshadows the "I" with such a strong weness (collective self) of fusion and interrelatedness it become 
imperative to explore the changes in the self image as a result of caregiving.

Content analysis brings to few significant responses categories viz: (1) Discontented \& dissatisfied with self (2) Felt good (3) Sympathetic (4) Compassionate (5) Don't know and Content analysis for Self Image after caregiving brings to fore few responses categories viz: (1) Disappointed (2) Felt good (3) Empathetic (4) Angry \& unhappy with self (5) Don't know.

While $82 \%$ of female caregivers felt that they were "sympathetic" towards others prior to caregiving however after caregiving (as of now) reported a lot of annoyance and felt nobody was happy in terms of "Angry \& unhappy with self" with him (84\%) narratives like:

\section{For the female caregiver the narrative: self image prior caregiving}

"Not taking life for granted, maintaining a meaningful life.... Before caregiving as a person i was very Sympathetic, calm and were able to develop strategies to deal with the difficult situation I and my family encountered because i was understand others feeling better than others.........I was Always set a goal for life and lived my life accordingly..... A meaningful life could be spending quality time together or doing things together so always enjoyed my life with my family" (A63).

"Before marriage, when I saw someone mistreating a mentally ill person, then I thought how people cry after doing a little service..... I was advising people that they were mentally ill, they are not crazy, they are also humans..."(A70)

\section{For the female caregiver the narrative: self image after caregiving}

"I get up in the morning ... I sweep the grounds ... after that start my day with make tea for family.... then I light the firewood stove for breakfast, then I go up and do the work of the cow (milking)..... like that there is much work all day for me that I do ... boil the milk, warm water for bathing, gave medicines to the patient.... if my mother-in-law had been around she'd never helped me, No one is happy, I am very upset all of these thing, everything is changed now"(A63).

"I have many roles in my life! As a daughterin-law of the house, as a wife....mother... I've to suffer a lot ... there are many problems like my children(34years) also need care, children need to be taught. ... and I bring them from school and I take them to school myself ... when they get sick I've to take them to the hospital too....... I keep on running whole day....no time for my family, for my children"s and not even for myself too.....this is not me....."(A77).

On the other hand their counterparts predominantly $(72 \%)$ reported a very positive self image in form of "Felt good" prior to caregiving and felt extremely "disappointed" and self defeated (84\%) after providing the care viz:

\section{For the male caregiver the narrative: self image prior caregiving}

"I really didn't have any problems, that I can recall......I used to be very good at reading, was the fastest in class, used to do all the work very easily .......... I used to be very happy before" (A21).

"Before, I used to sleep for 8 to 10 hours...... I used to wake up in the morning and exercise... I enjoyed life very much that time I want to do something new........My friend circle was very big and very popular.......Don't like negative views of anyone, very optimistic person i was......very much motivated \& curious for learn new things"'(A13)

\section{For the male caregiver the narrative: self-image after caregiving}

"I have recurring themes. One of them is that my money gets stolen by my relatives and friends... and another recurring theme for me is either taking an exam that I can't finish.... I am trying, but I am unable to, being late for my class at college... feel so much depressed and disappointed"(A40).

"I won't sleep well........ At times, I am unable to do anything correctly, I do not understand why this is happening......... I just determined that it was all stress, so I started taking counselling for that, and I'm still on that same medication......feel uncertain, loss of interest in socialization and a lack of motivation, with the feeling of intense loneliness" (A29).

Female caregivers, being culturally expected to provide care to parents-in-law, husband, child etc. As in other contexts, though women provided greater time and effort and support exchanges compared to men, they were less likely to experience reciprocity in the support they received [46, 47]. 


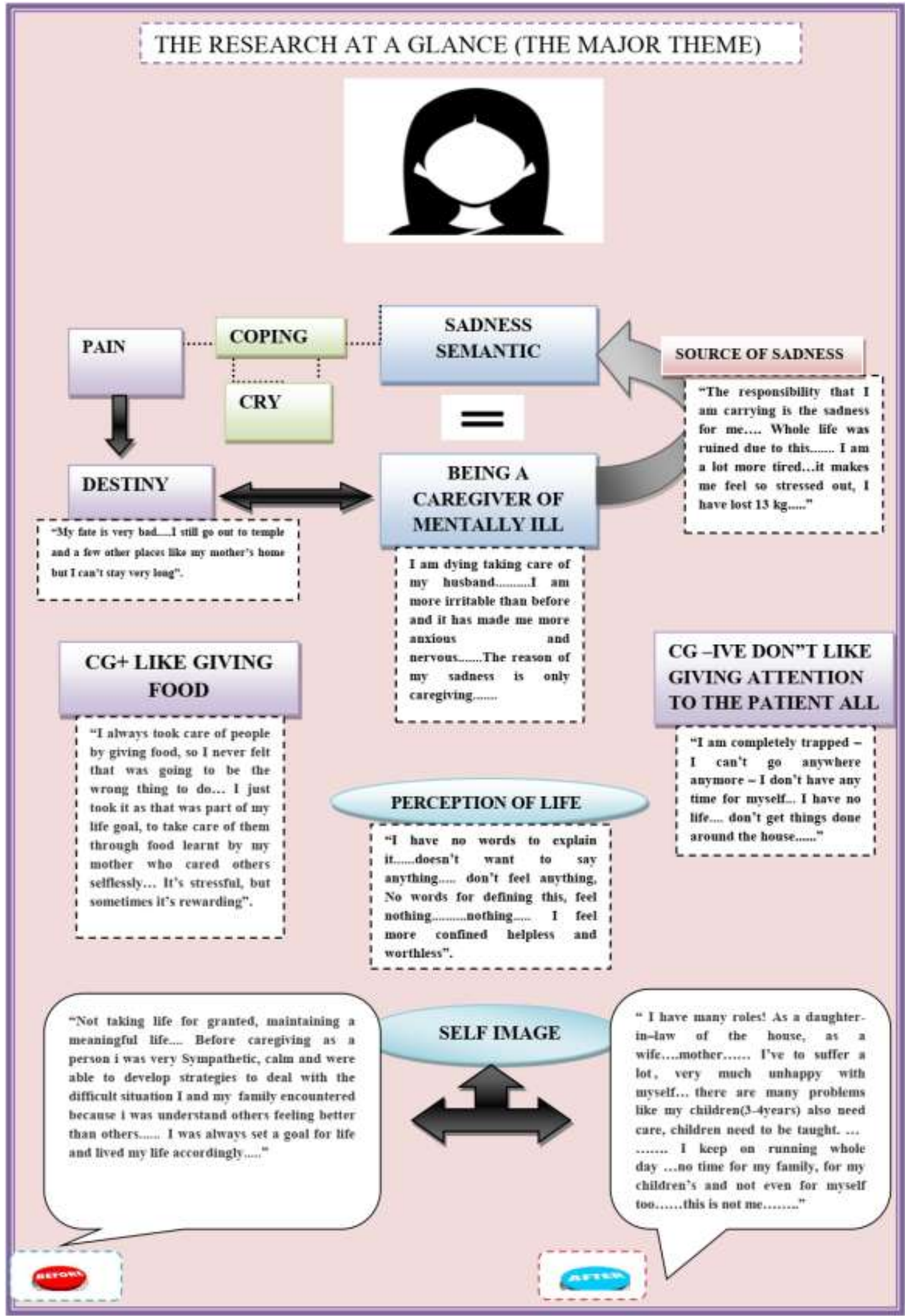




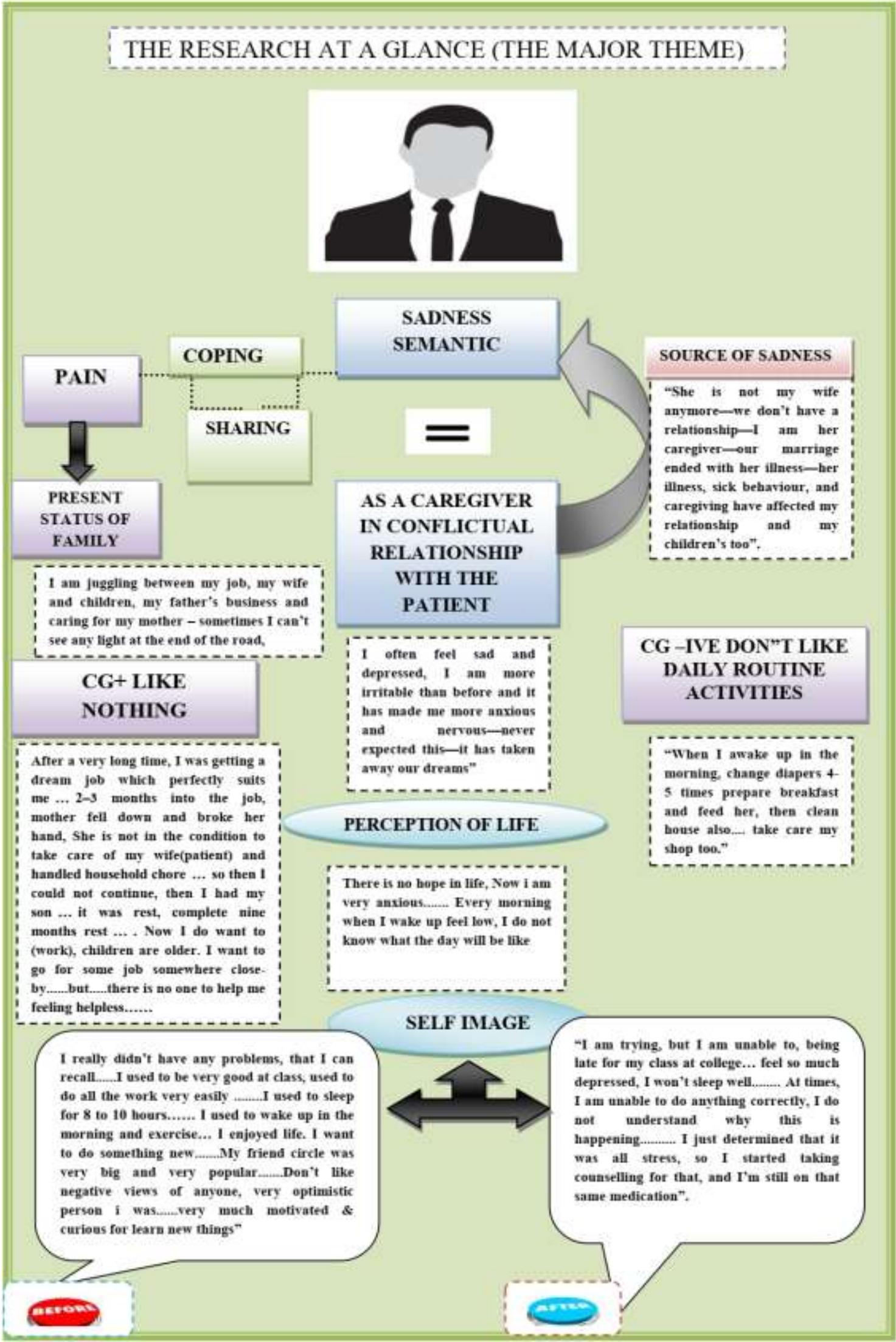

\section{CONCLUSION}

The present study on the one hand, has created a platform for the caregivers of patient with chronic mental illness to voice their hopelessness, pain and frustration which they have not been able to ventilate for a long period. On the other hand, it also brings to fore the need to create intervention for emotional wellbeing of the caregivers of the patient suffering from 
chronic mental illness. The mental health model which advocates mental health to be an issue of public health needs to be implemented for all three stages- primary, secondary and tertiary intervention which would sensitize the community and people at large for mental health issues, providing social support, as well as, "know how" of mental illness and its management to the caregivers of such patients.

The researchers also suggest more research tuned to narrative medicine to facilitate healing for both the patient as well as the caregiver.

\section{REFERENCES}

1. Han, B., \& Haley, W. E. (1999). Family caregiving for patients with stroke: review and analysis. Stroke, 30(7), 1478-1485.

2. Goldstein, N. E., Concato, J., Fried, T. R., Kasl, S. V., Johnson-Hurzeler, R., \& Bradley, E. H. (2003). Factors associated with caregiver's burden among caregivers of terminally ill patients with cancer. Journal of palliative care, 20(1), 38-43.

3. Grunfeld, E., Coyle, D., Whelan, T., Clinch J., Reyno, L., Earle, C. C., \& Glossop, R. (2004). Family caregiver burden: results of a longitudinal study of breast cancer patients and their principal caregivers. Cmaj, 170(12), 1795-1801.

4. Morimoto,T., Schreiner, A.S.,\& Asano, H. (2003). Caregiver burden and health- related quality of life among Japanese stroke Caregivers. Age and Ageing, 32(2), 218-223.

5. Marsh, N. V., Kersel, D. A., Havill, J. H., \& Sleigh, J. W. (1998). Caregiver Burden at One year following severe traumatic brain injury. Brain Injury, 12(12), 1045-1059.

6. Chio, A., Gauthier, A., Calvo, A., Ghiglione, P., \& Mutani, R. (2005). Caregiver burden and patients' perception of being a burden in ALS. Neurology, 64(10), 1780-1782.

7. Basavaraj, K. H., Navya, M. A., \& Rashmi, R. (2010). Quality of life in HIV/AIDS. Indian journal of sexually transmitted diseases and AIDS, 31(2), 75-80.

8. Surur, A. S., Teni, F. S., Wale, W., Ayalew, Y., \& Tesfaye, B. (2017). Health related quality of life of HIV/AIDS patients on highly active anti-retroviral therapy at a university referral hospital in Ethiopia. BMC health services research, 17(1), 1-8.

9. Soleimani, M. A., Zarabadi-Pour, S., Motalebi, S. A., \& Allen, K. A. (2020). Predictors of Quality of Life in Patients with Heart Disease. Journal of Religion and Health, 1-14.

10. Thompson, D. R., \& Yu, C. M. (2003). Quality of life in patients with coronary heart disease-I: assessment tools. Health and quality of life outcomes, 1, 42.

11. Strine, T. W., Chapman, D. P., Balluz, L. S., Moriarty, D. G., \& Mokdad, A. H. (2008). The associations between life satisfaction and healthrelated quality of life, chronic illness, and health behaviors among US community-dwelling adults. Journal of community health, 33(1), 40-50.

12. Sharma, N., Chakrabarti, S., \& Grover, S. (2016). Gender differences in caregiving among familycaregivers of people with mental illnesses. World journal of psychiatry, 6(1), 7.

13. Vishwakarma, A. K., Ghalsasi, P. S., Navamoney, A., Lan, Y., \& Powell, A. K. (2011). Structural phase transition and magnetic properties of layered organic-inorganic hybrid compounds: pHaloanilinium tetrachlorocuparate (II). Polyhedron, 30(9), 1565-1570.

14. Falasca, K., Mancino, P., Ucciferri, C., Dalessandro, M., Manzoli, L., Pizzigallo, E., ... \& Vecchiet, J. (2009). Quality of life, depression, and cytokine patterns in patients with chronic hepatitis $\mathrm{C}$ treated with antiviral therapy. Clinical and Investigative Medicine, E212-E218.

15. Casellas, F., López-Vivancos, J., Casado, A., \& Malagelada, J. R. (2002). Factors affecting health related quality of life of patients with inflammatory bowel disease. Quality of life research, 11(8), 775781.

16. Kate, N., Grover, S., Kulhara, P., \& Nehra, R. (2013). Relationship of caregiver burden with coping strategies, social support, psychological morbidity, and quality of life in the caregivers of schizophrenia. Asian journal of psychiatry, 6(5), 380-388.

17. Caqueo-Urízar, A., Gutiérrez-Maldonado, J., Ferrer-García, M., \& Darrigrande-Molina, P. (2012). Burden of care in Aymara caregivers of patients with schizophrenia. Revista de Psiquiatría y Salud Mental (English Edition), 5(3), 191-196.

18. Durmaz, H., \& Okanll, A. (2014). Investigation of the effect of self-efficacy levels of caregiver family members of the individuals with schizophrenia on burden of care. Archives of Psychiatric Nursing, 28(4), 290-294.

19. Yang, X., Hao, Y., George, S. M., \& Wang, L. (2012). Factors associated with health-related quality of life among Chinese caregivers of the older adults living in the community: a crosssectional study. Health and Quality of Life Outcomes, 10(1), 143.

20. Dalui, A., Guha, P., De, A., Chakraborty, S., \& Chakraborty, I. (2014). Assessment of stress \& related albuminuria in caregivers of severe mentally ill persons. The Indian Journal of Medical Research, 139(1), 174.

21. Yıkılkan, H., Aypak, C., \& Görpelioğlu, S. (2014). Depression, anxiety and quality of life in caregivers of long-term home care patients. Archives of psychiatric nursing, 28(3), 193-196.

22. Wong, D. F. K., Lam, A. Y. K., Chan, S. K., \& Chan, S. F. (2012). Quality of life of caregivers with relatives suffering from mental illness in Hong Kong: roles of caregiver characteristics, caregiving burdens, and satisfaction with psychiatric 
services. Health and quality of life outcomes, 10(1), 15.

23. Carroll, D. (2008). 'The Core Resource'the role of informal caretakers of the mentally Ill as seen in Uganda.

24. Verma, A., Cairns, J. A., Mitchell, L. B., Macle, L., Stiell, I. G., Gladstone, D., ... \& Ivers, N. (2014). 2014 focused update of the Canadian Cardiovascular Society Guidelines for the management of atrial fibrillation. Canadian Journal of Cardiology, 30(10), 1114-1130.

25. Leow, M. Q. H., \& Chan, S. W. C. (2011). Factors affecting caregiver burden of terminally ill adults in the home setting-A systematic review. JBI Database of Systematic Reviews and Implementation Reports, 9(45), 1883-1916.

26. Schulz, R., \& Williamson, G. M. (1991). A 2-year longitudinal study of depression among Alzheimer's caregivers. Psychology and Aging, 6, 569-578.

27. Pruchno, R. A., \& Resch, N. L. (1989). Husbands and wives as caregivers: Antecedents of depression and burden. The Gerontologist, 29(2), 159-165.

28. Young, R. F., \& Kahana, E. (1989). Specifying caregiver outcomes: Gender and relationship aspects of caregiving strain. The Gerontologist, 29(5), 660-666.

29. Williamson, G. M., \& Schulz, R. (1990). Relationship orientation, quality of prior relationship, and distress among caregivers of Alzheimer's patients. Psychology and Aging, 5(4), 502.

30. Parks, S. H., \& Pilisuk, M. (1991). Caregiver burden: Gender and the psychological costs of caregiving. American Journal of Orthopsychiatry,61, 501-509.

31. Tennstedt, S. L., Cafferata, G. L., \& Sullivan, L. (1992). Depression among caregivers of impaired elders. Journal of Aging and Health, 4, 58-76.

32. Lutzky, S. M., \& Knight, B. G. (1994). Explaining gender differences in caregiver distress: the roles of emotional attentiveness and coping styles. Psychology and aging, 9(4), 513.

33. Collins, C., \& Jones, R. (1997). Emotional distress and morbidity in dementia carers: a matched comparison of husbands and wives. International Journal of Geriatric Psychiatry, 12(12), 11681173.

34. Rose-Rego, S. K., Strauss, M. E., \& Smyth, K. A. (1998). Differences in the perceived well-being of wives and husbands caring for persons with Alzheimer's disease. The Gerontologist, 38(2), 224230.

35. del- Pino- Casado, R., Frías- Osuna, A., Palomino- Moral, P. A., \& Ramón Martínez-
Riera, J. (2012). Gender differences regarding informal caregivers of older people. Journal of Nursing Scholarship, 44(4), 349-357.

36. Akpınar, B., Küçükgüçlü, Ö., \& Yener, G. (2011). Effects of gender on burden among caregivers of Alzheimer's patients. Journal of nursing scholarship, 43(3), 248-254.

37. Serrano-Aguilar, P. G., Lopez-Bastida, J., \& Yanes-Lopez, V. (2006). Impact on health-related quality of life and perceived burden of informal caregivers of individuals with Alzheimer's disease. Neuroepidemiology, 27(3), 136-142.

38. Duru Aşiret, G., \& Kapucu, S. (2013). Burden of Caregivers of Stroke Patients. Turkish Journal of Neurology/Turk Noroloji Dergisi, 19(1).

39. Srivastava, G., Tripathi, R. K., Tiwari, S. C., Singh, B., \& Tripathi, S. M. (2016). Caregiver burden and quality of life of key caregivers of patients with dementia. Indian journal of psychological medicine, 38(2), 133.

40. Corcoran, M. A. (1992). Gender differences in dementia management plans of spousal caregivers: implications for occupational therapy. American Journal of Occupational Therapy, 46(11), 10061012.

41. Bush, E.C. (1997). Gender differences in specific caregiver burdens. Master's thesis. The University of Utah.

42. Almada, A.Z. (2001). Gender and caregiving: a study among Hispanic and non-Hispanic white frail elders. Master's Thesis. Virginia Polytechnic Institute and State University.

43. Campbell, P., Wright, J., Oyebode, J., Job, D., Crome, P., Bentham, P., ... \& Lendon, C. (2008). Determinants of burden in those who care for someone with dementia. International Journal of Geriatric Psychiatry: A journal of the psychiatry of late life and allied sciences, 23(10), 1078-1085.

44. AARP Public Policy Institute \& National Alliance for Caregiving. (2015). Caregiving in the US.

45. Perlick, D. A., Rosenheck, R. A., Miklowitz, D. J., Chessick, C., Wolff, N., Kaczynski, R., ... \& STEP- BD Family Experience Collaborative Study Group. (2007). Prevalence and correlates of burden among caregivers of patients with bipolar disorder enrolled in the Systematic Treatment Enhancement Program for Bipolar Disorder. Bipolar Disorders, 9(3), 262-273.

46. Ashwin, S., Tartakovskaya, I., Ilyina, M., \& Lytkina, T. (2013). Gendering reciprocity: solving a puzzle of nonreciprocation. Gender \& society, 27(3), 396-421.

47. Navaie-Waliser, M., Spriggs, A., \& Feldman, P. H. (2002). Informal caregiving: differential experiences by gender. Medical care, 1249-1259. 